\title{
Dificuldades encontradas pelos pecuaristas na implantação da rastreabilidade bovina
}

[Difficulties encountered by farmers in the implementation of traceability bovine]

\author{
M.A. Lopes $^{1,4}$, A.A. Demeu $^{2}$, A.D.B. Ribeiro ${ }^{3}$, C.M.B.M. Rocha ${ }^{1}$, F.R.P. Bruhn ${ }^{2}$, P.L. Retes ${ }^{3}$ \\ ${ }^{1}$ Universidade Federal de Lavras - UFLA - Lavras, MG \\ ${ }^{2}$ Alunos de pós-graduação - Universidade Federal de Lavras - Lavras, MG \\ ${ }^{3}$ Alunos de graduação - Universidade Federal de Lavras - Lavras, MG \\ ${ }^{4}$ Bolsista de produtividade do $\mathrm{CNPq}$
}

\begin{abstract}
RESUMO
Esta pesquisa teve como objetivo realizar o levantamento das dificuldades encontradas pelos pecuaristas que aderiram ao Serviço de Rastreabilidade da Cadeia Produtiva de Bovinos e Bubalinos (Novo SISBOV). Elaborou-se um formulário qualitativo semiestruturado, contendo 37 questões. Foram entrevistados 130 produtores de gado de corte em três grandes exposições agropecuárias durante o ano de 2009. Desses, aproximadamente 17\% (22 produtores) haviam aderido ao novo SISBOV. Foram entrevistados mais 49 pecuaristas em suas respectivas fazendas rastreadas, totalizando assim 179 entrevistas. As principais dificuldades encontradas pelos pecuaristas foram: mudanças frequentes nas normas do novo SISBOV, perda de elemento de identificação, remuneração inadequada pelos animais rastreados por parte dos frigoríficos e instabilidade de mercado.
\end{abstract}

Palavras-chave: bovinocultura de corte, rastreabilidade, segurança alimentar

\begin{abstract}
This research aimed to conduct a survey of the difficulties encountered by farmers who joined the Service of Supply Chain Traceability of Cattle and Buffaloes (New SISBOV). A semi-structured qualitative form containing thirty-seven questions was elaborated. We interviewed 130 beef cattle farmers farming in three major exhibitions during year 2009, among which $17 \%$ (22 farmers) had joined the new SISBOV. We interviewed over 49 farmers in their screened farms, thus totaling 179 interviews. The main difficulties encountered by farmers were: frequent changes in new SISBOV rules, loss of proof of identity, inadequate remuneration for animals tracked by the stores and market instability.
\end{abstract}

Keywords: beef cattle, food safety, traceability

\section{INTRODUÇÃO}

A rastreabilidade da carne bovina começou a tomar corpo na Europa, por volta de 1996, especialmente com o advento da doença da vaca louca, da febre aftosa e da contaminação de alimentos pelas dioxinas, que colocaram em destaque a absoluta necessidade da busca de métodos cada vez mais seguros para realizar o acompanhamento, não só da vida dos animais, mas de todo o trânsito, estocagem e comercialização do seu produto.
A exigência da rastreabilidade da carne por parte desse bloco econômico trouxe grande inquietação aos países exportadores e em especial ao Brasil, em virtude do tamanho do rebanho, das condições de criação do gado, da extensão do território brasileiro e da falta de utilização da tecnologia por parte da grande maioria de produtores ainda não acostumada com o uso da informática ou da gerência e controles integrados ao dia a dia de suas atividades. Diante disso, o governo brasileiro criou, em 2002, o Sistema Brasileiro de Identificação e

Recebido em 25 de junho de 2011

Aceito em 7 de agosto de 2012

Email: malopes@dmv.ufla.br

Apoio financeiro: FAPEMIG (CVZ - APQ-00607-08) 
Certificação de Origem Bovina e Bubalina (SISBOV). Após muitas discussões, debates e pressões, foram realizadas alterações e publicadas várias outras instruções normativas, modificando inclusive a obrigatoriedade do SISBOV. Em 2006 a Instrução Normativa (IN) $\mathrm{n}^{\mathrm{o}} 17$, de 13 de julho, foi publicada e surgiu o novo SISBOV, cujas modificações pretenderam dar maior credibilidade ao processo.

Desde a primeira IN ( $\mathrm{n}^{\circ} 01$, de 09/01/2002), muitas discussões têm ocorrido. A imposição pelo governo federal a princípio, a publicação de novas IN, revogações de outras; tudo isso tem gerado muito polêmica e tem havido entrave na rastreabilidade brasileira. $\mathrm{Na}$ implantação do novo SISBOV, por ser ainda recente, tanto os pecuaristas, as certificadoras, bem como os frigoríficos, ainda vivenciam algumas dificuldades. Diante disso, esta pesquisa teve como objetivo realizar o levantamento das dificuldades encontradas pelos pecuaristas que aderiram ao novo SISBOV. Especificamente pretendeu-se obter informações importantes, tais como: se os produtores conhecem e como conheceram o SISBOV; método de identificação utilizado; custo, vantagens e desvantagens da implantação; a opinião em relação ao novo SISBOV e o futuro da rastreabilidade. Espera-se que, com o levantamento das dificuldades enfrentadas por esse importante segmento do agronegócio, o da carne, seja possível sugerir propostas para sanar tais dificuldades.

\section{MATERIAL E MÉTODOS}

Elaborou-se um formulário qualitativo semiestruturado, contendo 37 questões, baseado no trabalho de Lopes et al. (2007), porém adaptado e acrescido de mais questões. Esse foi aplicado em feiras de bovinos de corte, as quais reúnem produtores de todo o país. Dessa forma as escolhidas foram a EXPOZEBU, em Uberaba (MG), em maio de 2009, a SUPERAGRO em Belo Horizonte (MG) e a FEICORTE em São Paulo, ambas em junho de 2009. Diante da baixa quantidade de produtores que rastreavam seus animais, foi necessário buscar fazendas nos estados que rastreavam e, assim, 47 produtores de Minas Gerais foram entrevistados, e mais dois pecuaristas: um em Mato Grosso e outro em Alagoas, no período de 21 de setembro a 30 de abril de 2010.
Os dados foram cadastrados no software Epidata $3.1^{\circledR}$ e analisados por meio de estatísticas descritivas, utilizando o SPSS $17.0^{\circledR}$. Algumas variáveis qualitativas de interesse relacionadas à percepção dos pecuaristas sobre a rastreabilidade e ao SISBOV no Brasil foram transformadas em dicotômicas (Zero ou Um) por "análise de conteúdo" (Minayo, 1993), sendo que a medida de qualidade igual a um corresponde àquelas respostas que representam percepções favoráveis dos pecuaristas em relação ao SISBOV e à rastreabilidade bovina no Brasil.

Para testar a associação entre as variáveis levantadas, conjuntamente foi realizada uma análise multidimensional de componentes principais (Rocha, 2005). Foram utilizados os testes de Kaiser-Meyer-Olkin (KMO) (mínimo de 0,5) e de esfericidade de Bartlett (mínimo de 0,05) para aferição da qualidade das correlações entre as variáveis. Foram considerados os eixos (componentes) que obtiveram valores próprios (eigenvalues) iguais ou superiores a 1(um), com inércia mínima de $70 \%$ no último eixo obtido. Assim, no modelo final que atingiu os valores mínimos nesses testes foram avaliadas as percepções dos pecuaristas sobre o manejo nas propriedades (Manejo) ( $0=$ dificulta; $1=$ facilita); custo da rastreabilidade (Custo) $(0=$ alto; $1=$ baixo a acessível); facilidade de entendimento da legislação que regulamenta a rastreabilidade e o SISBOV (Legislação) (0=não; $1=$ razoável a sim); remuneração dos frigoríficos em relação aos animais rastreados (RemFrig) ( $0=$ igual/pior; $1=$ =melhor); e a sua opinião sobre um futuro promissor do SISBOV (Futuro) ( $0=$ não; $1=$ sim). Desse modo, quanto mais próximo de 1 (um) melhor a percepção, e quanto mais próximo de zero, pior. A consistência interna dos fatores de interesse após essa análise também foi medida por meio do alpha de Cronbach, cujo valor mínimo considerado foi de 0,6 .

\section{RESULTADOS E DISCUSSÃO}

Foram abordadas 523 pessoas, sendo que 360 (69\%) eram produtores de outras atividades do agronegócio, profissionais da área ou visitantes, que vão às feiras por entretenimento. Dos abordados, apenas $163(31 \%)$ eram produtores de gado de corte; desses, 20\% (33 produtores) optaram por não participarem da entrevista. Assim, foram entrevistados 130 produtores de gado de corte nas exposições e feiras e outros 49 
pecuaristas, que utilizavam o rastreamento, em suas respectivas fazendas. Desse total de 179 pecuaristas, aproximadamente $40 \% \quad$ (71 produtores) haviam aderido ao novo SISBOV. Todos os 71 produtores responderam a todas as 37 questões e, em alguns casos, preferiram não opinar. Em certas questões, dadas várias alternativas, o pecuarista podia escolher mais de uma.

Os produtores que praticam engorda somente, ou engorda e mais algum tipo de exploração, foram a maioria $(65,3 \%$; Tab. 1). Esse percentual é justificado devido à revogação dos incisos VIII e IX, do artigo 13, e inciso VII, do artigo 14, do capítulo IV, da IN n ${ }^{\circ} 17$, de 13 de julho de 2006, que dispõe que somente será permitido o ingresso de bovinos e bubalinos no ERAS Estabelecimento rural aprovado no SISBOV se tiver origem em outro ERAS; pela IN $n^{\circ} 24$, de
30 de Abril de 2008 e IN n ${ }^{\circ} 25$, de 12 de junho de 2007. Com essa revogação, os pecuaristas que realizavam cria e/ou recria não se interessaram em rastrear seus animais, já que lhes caberia o custo e o trabalho de implantar o sistema e, no momento de comercializar os animais, não receberiam um valor adicional por arroba. Tal bonificação ocorre apenas por ocasião da venda ao frigorífico. Dos pecuaristas que rastreavam os animais, $83 \%$ consideraram a revogação favorável, porque diminuía a oportunidade de compra e negociação.

Dos pecuaristas que possuíam animais rastreados, 60\% exportavam para o mercado externo; $25 \%$ para o mercando interno e externo; $13 \%$ para o mercado interno; e $2 \%$ não tinham conhecimento para qual mercado o produto era destinado.

Tabela 1. Explorações desenvolvidas pelos pecuaristas entrevistados

\begin{tabular}{|c|c|c|}
\hline Exploração desenvolvida & Quantidade & $(\%)$ \\
\hline Ciclo completo & 45 & 25,1 \\
\hline Recria e engorda & 33 & 18,4 \\
\hline Cria e Recria & 22 & 12,3 \\
\hline Engorda & 21 & 11,7 \\
\hline Elite & 14 & 7,8 \\
\hline Cria & 13 & 7,3 \\
\hline Ciclo completo e elite* & 12 & 6,7 \\
\hline Cria, recria e elite* & 7 & 3,9 \\
\hline Recria & 4 & 2,2 \\
\hline Engorda e elite* & 3 & 1,7 \\
\hline Cria e engorda & 2 & 1,1 \\
\hline Cria e elite* & 2 & 1,1 \\
\hline Recria, engorda e elite* & 1 & 0,6 \\
\hline Total & 179 & 100 \\
\hline
\end{tabular}

* Animais de genética superior, destinados à venda como reprodutores.

Quando perguntados se tinham conhecimento da legislação que regulamenta o novo SISBOV, $33 \%$ responderam que não; apenas $10 \%$ mencionaram que conheciam toda a legislação e práticas do campo; $7 \%$ responderam que conheciam somente as práticas de campo; e 50\%, que conheciam em parte a legislação e as práticas de campo. Desses que responderam ter algum conhecimento sobre a legislação, $41 \%$ consideraram a legislação de difícil entendimento; $33 \%$ disseram que há partes fáceis e algumas difíceis de serem entendidas; e 26\%, que a legislação é de fácil entendimento. É de suma importância que os produtores tenham conhecimento da legislação e entendimento da mesma, sendo essa a base para que possa ser realizado um bom trabalho dentro da propriedade e a rastreabilidade tenha êxito. Portanto, é necessário buscar o aumento da difusão dessas informações ao produtor, por meio de palestras, dias de campo, boletins, etc., a fim de conscientizar tanto os produtores como os consumidores da importância de rastrear a carne bovina.

Quando perguntados se a legislação requer muitos documentos para se tornar um ERAS, ou para permanecer como um ERAS, 55\% responderam que sim, mas que está dentro do esperado; $42 \%$, que deveria ser um método mais 
conciso, mais direto e automático; e somente $3 \%$ disseram que não são requeridos muitos documentos. Ainda foi questionado, em relação aos ERAS, se consideravam benefício ou malefício, $51 \%$ consideraram um benefício, concedendo um prestígio à fazenda; para $42 \%$, que era um malefício, já que todo o rebanho tem de ser rastreado, mas que muitas vezes é vendido para o mercado interno; e 7\% declararam que era indiferente, que não trazia nem benefício nem malefício. Na Austrália, segundo Beasley (2002), os pecuaristas tiveram as mesmas dúvidas dos brasileiros, mas já estão percebendo que a rastreabilidade, além de ser uma exigência europeia, é também uma forma de aumentar a eficiência na produção de carne em suas fazendas.

Foi questionado aos produtores que não rastreavam seus animais (46\%) se pretendiam rastrear. Desses, 64\% responderam que não e $20 \%$ justificaram dizendo que não havia credibilidade no sistema, que a legislação mudava com muita frequência e que isso gera instabilidade para o produtor; $20 \%$ relataram que não trabalhavam com animais de terminação e que, portanto, não era necessário rastrear; $10 \%$ relataram que o custo para aderir ao novo SISBOV é alto; $10 \%$, que era muito trabalho sem benefício; $10 \%$ não possuem interesse em vender para o mercado externo; aproximadamente $8 \%$ falaram que a região não absorve e que não há frigoríficos que exportam nas proximidades da propriedade; ainda houve pecuaristas que informaram não ter interesse por não ser economicamente viável (5\%); outros disseram que, pelo fato de os animais já serem rastreados, a ABCZ (Associação Brasileira de Criadores de Zebu) poderia realizar esse trabalho, e que falta incentivo por parte dela (7\%); outros falaram não ter interesse por não ser exigido $(8 \%)$; e ainda aqueles que nunca pensaram a respeito $(2 \%)$.

No Brasil são permitidos quatro métodos de identificação. Desses, os mais utilizados pelos pecuaristas foram o brinco e botão $(90 \%)$; brinco e marca a ferro quente (6\%); brinco e tatuagem (3\%); brinco e dispositivo eletrônico - implante na orelha $(1 \%)$.

Para $78 \%$ dos pecuaristas, os dispositivos de identificação são satisfatórios, e o uso de dois identificadores fornece segurança caso haja perda de um identificador; $9 \%$ consideram que deveria haver outros mais eficientes; para $7 \%$, os identificadores não são satisfatórios e consideraram que deveria haver somente um método, padronizado; entretanto, para $6 \%$ é satisfatório, mas um método já seria suficiente.

A Austrália se destaca como um dos países mais avançados na rastreabilidade. O programa se baseia em identificação individual dos animais, podendo ser por brinco eletrônico ou bollus ruminal. Pelo uso de identificadores por radiofrequência, os pecuaristas têm um grande incremento no gerenciamento da propriedade (Government..., 2010).

Os produtores foram ainda questionados em relação aos custos de implantação do novo SISBOV. Aproximadamente $51 \%$ o consideram acessível; $30 \%$, alto; $16 \%$, que é adequado pelo benefício que gera, ou seja, eles consideram que há benefícios na propriedade e retorno financeiro. Quando questionados sobre o valor do custo, $22 \%$ não sabiam. Dos $78 \%$ que sabiam, $16 \%$ disseram que o custo varia de $\mathrm{R} \$ 2,00$ a $\mathrm{R} \$ 4,00 ; 78 \%$, de $\mathrm{R} \$ 4,90$ a $\mathrm{R} \$ 10,00 ; 6 \%$, de $\mathrm{R} \$ 10,30$ a $\mathrm{R} \$ 15,00$ por animal. Essa variação pode ser justificada, pois, segundo Lopes et al. (2008), o custo da implantação da rastreabilidade é dependente da empresa certificadora (valor da taxa de inscrição, de rastreabilidade por animal e da anuidade), do valor da visita do técnico (salário e deslocamento), bem como do tipo de identificador utilizado.

Sobre a remuneração por parte dos frigoríficos, $21 \%$ relatou que foi melhor, mas com respostas variadas (de $\mathrm{R} \$ 0,50$ a $\mathrm{R} \$ 11,00$ acrescidos por arroba). Tal variação, segundo Schüller e Lopes (2011), deveu-se à baixa disponibilidade de animais para abate, em decorrência dos descredenciamentos de ERAS, devido ao decreto de embargo à carne brasileira por parte da União Europeia, em 30 de janeiro de 2008. Dos 8.000 ERAS cadastradas no novo SISBOV, apenas 2.681 foram selecionados para auditoria; no entanto, a União Europeia informou ao Brasil que selecionaria apenas 300. Destes, apenas 106 atenderam às exigências de certificação e rastreabilidade, sendo autorizados inicialmente a exportar carne bovina in natura.

Quando perguntados sobre a auditoria realizada, grande parte $(69 \%)$ relatou que era rápida; $23 \%$ disseram que havia espera e que esta era 
moderada; para outra parte, a visita para auditoria era demorada para acontecer (8\%), levando meses de espera. Esses mesmos pecuaristas observaram que a visita demorava aproximadamente dois meses (33\%); cinco meses $(34 \%)$ e até mesmo doze meses (33\%). Observou-se que o período de espera foi diferente entre os estados: em Mato Grosso, dois meses; em Minas Gerais, cinco; Santa Catarina, doze.

Os produtores (89\%) ainda relataram que a auditoria é rigorosa, na qual um item não cumprido impede que a propriedade entre na Lista Traces (composta pelas propriedades aptas a exportar para a União Europeia); para os demais $(11 \%)$, a auditoria era flexível, podendo haver algumas falhas. Acredita-se que as respostas dos entrevistados variaram devido à não conformidade menor e maior, que consta no Formulário Check list, utilizado durante as auditorias.

A maioria dos entrevistados considerou os intervalos de vistorias para os ERAS (180 dias) e ERAS que confinam (60 dias) adequados, com 84 e $89 \%$, respectivamente; uma minoria achou inadequado ( $16 \%$ e $11 \%$ para os ERAS e ERAS que confinam, respectivamente), e mencionaram que o intervalo de visita deveria ser maior. Ainda em relação a prazo, $83 \%$ dos entrevistados consideram que o prazo para identificar os animais nascidos na propriedade é adequado; para $8 \%$ deveria haver mais tempo; e $9 \%$, que deveria ocorrer antes dos 10 meses. O tempo de transferência de um animal de um estabelecimento não aprovado para um aprovado pelo novo SISBOV foi questionado: $88 \%$ consideram que 30 dias para que ocorra a identificação é suficiente, enquanto que $12 \%$ julgam insuficiente, por haver muita burocracia.

Em relação ao manejo, a maioria $(83 \%)$ relatou que ficou mais difícil, mas que não prejudicou o trabalho na propriedade; a minoria $(5 \%)$ alegou que dificultou e prejudicou. No entanto, para $12 \%$, o manejo foi facilitado. A melhora no manejo deu-se, provavelmente, pelo fato de os animais estarem identificados, facilitando assim diversas práticas zootécnicas (Lopes et al.,
2007). Ainda nesse contexto, $76 \%$ falaram que o registro de informação exigido pelo novo SISBOV beneficia a empresa rural por proporcionar maior controle sobre a propriedade e o rebanho, enquanto que $12 \%$ acham que não traz benefício algum, e, para $12 \%$, há benefício pelo controle, no entanto é um problema por não haver mão de obra capacitada. Segundo $80 \%$ dos entrevistados, os dados coletados foram utilizados para calcular índices zootécnicos; $20 \%$ não utilizaram os dados para gerar informações.

A rastreabilidade melhora a gestão da empresa rural pela obrigatoriedade da identificação individual do animal, o que permite ao produtor manter registros de parentesco, data de nascimento, registros de produção, histórico de saúde e uma série de outras informações importantes para a gestão, garantindo tomadas de decisão precisas, além de fornecer a origem do animal (Lopes et al., 2007; Neary e Yager, 2009; Sybesma, 1991).

A mudança frequente nas leis foi a principal dificuldade encontrada, por ocasião da implantação do novo SISBOV, por $85 \%$ dos entrevistados (Tab. 2). Esse valor é bastante superior ao encontrado por Lopes et al. (2007) ao entrevistarem pecuaristas logo após a instituição do "antigo" SISBOV. A grande diferença é confirmada pelo histórico da rastreabilidade. De 10 de janeiro de 2002 - quando foi publicada a primeira instrução normativa, que instituiu o antigo SISBOV - até o dia 21 de dezembro de 2009, foram publicadas 25 instruções normativas. Dessas, 16 foram revogadas, e espera-se para os próximos meses a revogação de mais oito instruções normativas, como prevê a IN 65 de 16 de dezembro de 2009. Após a pesquisa realizada por Lopes et al. (2007), ou seja, do dia 31 de agosto de 2005 até março de 2010, já foram publicadas nove instruções normativas e uma Lei ( $\mathrm{n}^{\circ} 12.097$, de 24 de novembro de 2009), e revogadas 16 IN. Essa frequência de mudanças das normativas veio atrelada, segundo os produtores, à falta de divulgação (54\%), o que torna a situação ainda mais complicada para os produtores. 
Tabela 2. Dificuldades para implantar o novo SISBOV e manter a rastreabilidade

\begin{tabular}{lcc}
\multicolumn{1}{c}{ Dificuldades } & Respostas & $\%$ \\
\hline Mudanças frequentes da legislação & 60 & 85 \\
Perda de elemento de identificação & 47 & 66 \\
Qualidade do serviço das certificadoras & 41 & 58 \\
Falta de divulgação das leis & 38 & 54 \\
Custo elevado da certificação & 35 & 49 \\
Aplicação dos dispositivos de identificação & 35 & 49 \\
Escolha das certificadoras & 32 & 45 \\
Preencher as planilhas de identificação, entrada/saída e morte de animais & 17 & 24 \\
Controle do rebanho, nasc/morte (anot. em caderneta de campo) & 09 & 13 \\
\hline
\end{tabular}

Entre tantos países que rastreiam seus bovinos, o Brasil é o que mais teve mudanças na legislação. Em outros, como o Reino Unido, mudanças foram necessárias, mas não houve anulação de toda uma legislação e implantação de outra. Após o surto da febre aftosa em 2001, a legislação do Reino Unido sofreu mudanças, dando ênfase à movimentação de animais.

Outras dificuldades foram citadas; entre elas, merecem destaque a perda de elemento de identificação e a qualidade do serviço oferecido pelas certificadoras. Sobre essa qualidade, Rolim e Lopes (2005), ao realizarem estudo comparando a metodologia de trabalho de empresas certificadoras credenciadas pelo MAPA, salientaram que há necessidade de melhorar a fiscalização, pois nem todas as certificadoras estão aptas a prestar serviços de tamanha responsabilidade.

A análise de componentes principais dos indicadores de pecuaristas que aderiram ao novo SISBOV (Fig. 1) demonstrou a existência de correlação positiva entre as variáveis do componente 1 (definido pelas variáveis relacionadas ao aspecto financeiro): Custo, RemFrig e Futuro. Ou seja, os pecuaristas que acreditavam num futuro promissor da rastreabilidade bovina no Brasil tendem a considerar o custo da rastreabilidade acessível a baixo e que os frigoríficos pagavam melhor aos pecuaristas por animais rastreados em relação aos não rastreados. Isso demonstra uma visão de custo-benefício positiva. Além disso, considerando o quadrante, ou seja, a composição dos dois componentes, aqueles que têm uma visão de custo e futuro positiva, são os que têm um melhor conhecimento da legislação. Isso demonstra a importância da educação sanitária e de legislação para fomentar as melhorias tecnológicas no agronegócio; e também que há necessidade de buscar legislação mais adequada e duradoura, pois muitas mudanças trazem dificuldades na atualização dos produtores. As variáveis em conjunto mediram $61 \%$ das dificuldades encontradas pelos pecuaristas que aderiram ao novo SISBOV ( $\alpha$ de Cronbach do modelo $=0,61)$. Esse resultado foi considerado satisfatório, considerando a grande complexidade e dificuldade de mensuração do fenômeno estudado. Ao se considerar apenas as variáveis do componente 1 , o valor do $\alpha$ de Cronbach foi ainda maior $(0,65)$. Isso indica que o aspecto financeiro é um fator importante para os pecuaristas na sua percepção das dificuldades encontradas após aderir ao novo SISBOV.

A importância da certificação e da rastreabilidade para os pecuaristas também foi questionada. Para a maioria, a rastreabilidade confere maior controle na criação e abate de animais (77\%); assegura credibilidade, melhora as exportações e abre novos mercados consumidores $(76 \%)$; fornece conhecimento da origem e histórico da vida do animal (74\%); garante alimento de qualidade e saúde pública (73\%); gera maior controle do rebanho (73\%); permite identificar as deficiências, o que possibilita uma melhor gestão na pecuária (70\%). 


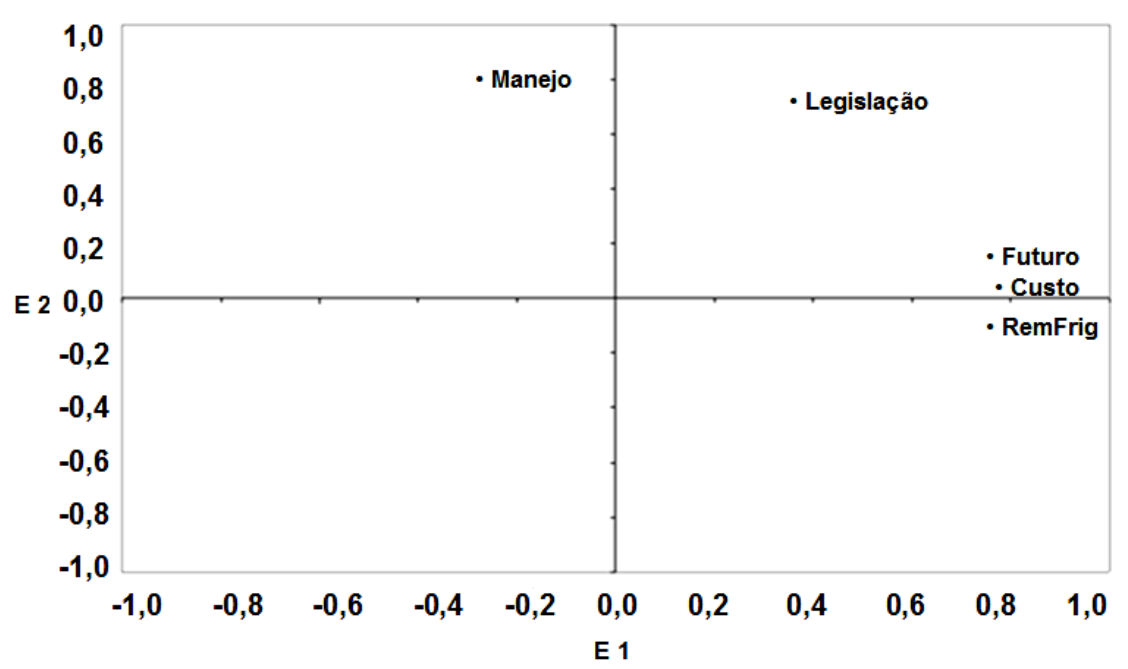

Inércia acumulada até o $2^{\circ}$ eixo: 72,4\%; Kaiser-Meyer-Olkin: 0,65; Bartlett <0,01.

MANEJO = percepção sobre a influência do SISBOV sobre o manejo nas propriedades ( $0=$ dificulta; $1=$ =facilita); CUSTO = percepção sobre o custo da rastreabilidade bovina ( $0=$ alto; $1=$ baixo a acessível); LEGISLAÇÃO = percepção sobre o entendimento da legislação que regulamenta a rastreabilidade bovina e o SISBOV ( $0=$ não; 1=razoável a sim); RemFrig = percepção de como os frigoríficos remuneram os animais rastreados em relação aos não rastreados $(0=$ igual/pior; $1=$ melhor $)$ FUTURO = percepção sobre um futuro promissor do SISBOV $(0=$ não; $1=\operatorname{sim})$.

Figura 1. Componentes principais dos indicadores de percepção de pecuaristas que aderiram ao Serviço de Rastreabilidade da Cadeia Produtiva de Bovinos e Bubalinos (SISBOV) no Brasil

Também foram ressaltadas as desvantagens na implantação do novo SISBOV. As principais se referem à remuneração inadequada pelos animais rastreados $(68 \%)$; seguida do custo elevado da certificação (49\%); burocracia na compra e venda de animais (45\%); a deficiência na mão de obra para registros na cardeneta de campo (45\%), o que mostra a importância de se investir na qualificação do homem do campo. Os pecuaristas ainda se mostraram preocupados com os dias de fiscalização, devido à mobilização de mão de obra (41\%); bem como com a movimentação e estresse dos animais nas vistorias $(43 \%)$ e durante o processo de identificação (40\%).

Ainda foi perguntado se eles acreditavam no futuro da rastreabilidade: $67 \%$ (120 pessoas) disseram que sim; $18 \%$ (32) falaram que não; e $15 \%$ (29) não quiseram opinar. As respostas dos pecuaristas mostram que eles estão preocupados com o agronegócio e com o futuro.

\section{CONCLUSÕES}

A rastreabilidade no Brasil tem passado por contínuas mudanças, deixando o produtor inseguro, tendo como consequência a baixa adesão ao novo SISBOV. As principais dificuldades encontradas pelos produtores estão diretamente relacionadas com as mudanças na legislação e a falta de divulgação dessas mudanças, além do custo elevado da certificação. Ainda assim, a grande maioria dos pecuaristas julga importante a rastreabilidade e acredita em seu futuro. Desse modo, é possível e necessário restaurar a credibilidade do novo SISBOV ante os pecuaristas. Incentivo financeiro é um ponto decisivo, aliado a campanhas de esclarecimentos em palestras, dias de campo e, principalmente, propagandas em televisão, rádios e revistas.

\section{AGRADECIMENTOS}

Os autores agradecem à FAPEMIG e ao $\mathrm{CNPq}$ pelo apoio na realização deste trabalho. 


\section{REFERÊNCIAS}

BEASLEY, R.O. O sistema australiano de rastreabilidade. 2002. Disponível em: <http://www.beefpoint.com.br/?noticiaID=4520 \&act $\mathrm{A}=7$ \&areaID $=15 \&$ secaoID $=125>$ Acessado em: 31 dez. 2010.

GOVERNMENT of south australia: primary indrustries and resources S.A. 2010. NLIS. Disponível em: <http://www.pir.sa.gov.au/_data/assets/pdf_file/ 0020/80561/NLIS.pdf> Acessado em: $30 \mathrm{dez}$. 2010.

LOPES, M.A.; SANTOS, G.; AMADO, G.B.; CARDOSO, M.G. Principais dificuldades encontradas pelos pecuaristas na implantação da rastreabilidade de bovinos. Cienc. Anim. Bras., v.8, p.515-520, 2007.

LOPES, M.A.; SANTOS, G.; AMADO, G.B. Viabilidade econômica da adoção e implantação da rastreabilidade em sistemas de produção de bovinos no Estado de Minas Gerais. Cienc. Agrotecnol., v.32, p.288-294, 2008.

MINAYO, M.C.S. O desafio do conhecimento: pesquisa qualitativa em saúde. 2.ed. São Paulo Rio de Janeiro: HUCITEC - ABRASCO, 1993, 269p.
NEARY, M.; YAGER, A. Methods of Livestock Identification .2009. Farm Animal Management @Purdue. Purdue University. Disponível em: <http://www.ces.purdue.edu/extmedia/AS/AS556-W.pdf, 2009>. Acessado em 13 dez. 2009.

ROCHA, C.M.B.M. Percepção e atitude de produtores de leite de Minas Gerais de diferentes estratos de produção em relação ao Boophilus microplus. 2005. 62f. Tese (Doutorado em Ciência Animal) - Escola de Veterinária da UFMG, Belo Horizonte.

ROLIM, F.J.; LOPES, M.A. Comparativo entre certificadoras de rastreabilidade bovina e bubalina oficialmente credenciadas pelo Ministério da Agricultura, Pecuária e Abastecimento (MAPA). Cienc. Agrotecnol., v.29, p.1052-1060. 2005.

SCHÜLLER, M.C.; LOPES, M.A. Alguns aspectos da rastreabilidade bovina e bubalina no Brasil. Lavras, UFLA. 2011. 40p. (Boletim Técnico, 87).

SYBESMA, W. Summary and conclusions. In: LAMBOOIJ, E. (Ed.). Automatic Eletronic Identification Systems for Farm Animals. Report CEC Series: Agriculture, n. eur.13198. Brussels, p.127-31, 1991 . 